\title{
Technical aspects of SAW gas sensors application in environmental measurements
}

\author{
Eukasz Guz ${ }^{1, *}$ \\ ${ }^{1}$ Lublin University of Technology, Faculty of Environmental Engineering, Nadbystrzycka 40B, 20-618 Lublin, Poland
}

\begin{abstract}
The development of semiconductor technology and computer methods allows for the improvements in air pollutions measurement techniques. Besides the traditional techniques of air pollution measurement such as chromatography or dynamic olfactometry, the electronic nose (EN) gains increasing attention in this area. EN is a device which imitates the human olfactory sense. The main component of the device is an array of many nonspecific gas sensors. In this article, the most frequently used types of gas sensors in scientific studies were shortly characterised as: metal oxide semiconductors (MOS), conducting polymers, quartz microbalances (QCM) and surface acoustic wave (SAW) sensors, and others. Both their advantages and disadvantages were summarised. Technical aspects of measurements using SAW gas sensors arrays were presented, as well as measurement circuits were described.
\end{abstract}

\section{Introduction}

In the field of gas pollution analysis, chromatography is unquestionably one of the most proven methods. It enables precise qualitative and quantitative analyses, but the costs of equipment and conducting research are still a barrier in many studies. As far as the measurements of odour compounds nuisance is concerned, the measurements using dynamic olfactometry are the most popular [1, 2]. Appropriately selected team, and measurements carried out according to strictly defined procedures enable to obtain objective results [3, 4].

Electronic nose systems, due to their continuous improvement, could be an interesting supplement to traditional measurement methods. Their usefulness can be demonstrated by the wide range of applications described in the scientific literature. EN systems were used for medicine diagnosis [5], food product quality assessment [6], in agriculture [7,8], in building industry [9] and many others [10-12].

In principle, the device imitates the sense of smell of organisms. The role of olfactory receptors is played by gas sensors, sensitive to detecting different groups of chemical compounds. Each gas mixture generates a different signal profile from all sensors, which is characteristic for a given substance. In this way, a possibility of creating identical responses of gas sensors array for different samples is minimised. For the further analysis of the measurement results, a multidimensional complex set of signals from all sensors is considered; therefore, multidimensional data analysis methods should be applied, such as PCA or artificial neural networks.
An important issue is the selection of sensors for the device. Both non-selective, general purpose sensors and high-selective sensors should be used to analyse pollutants typical for a selected emission source.

There are four main groups of sensors: optical, thermal, electrochemical and gravimetric. Each of these groups has specific advantages and disadvantages summarised in Table 1. Sensitivity of electrochemical sensors ranges approximately from 5 to $500 \mathrm{ppm}$. Gravimetric ones are able to detect even $1 \mathrm{ng}$ mass change of adsorbed gas molecules.

\section{SAW sensor}

\subsection{Principle of operation}

One of the methods of improving the sensors properties, involves examining new sensing materials in order to increase the sensors sensitivity and selectivity. The SAW sensors create a very good basis for the application of many types of sensing layers due to their construction and low working temperature.

The basis for SAW sensors operation is the piezoelectric effect. The electric charge on the surface of a piezoelectric material appeared as a result of mechanical strain. Piezoelectric material also exhibits the reverse phenomenon, involving changing dimensions of the crystal under the influence of the applied electric field.

The basic design of the SAW sensor is shown in Fig.1. At least one interdigital transducer (IDT) is formed on the surface of the piezoelectric. In typical solutions, there are two IDTs: input and output. The input IDT, under the influence of applied potential, causes changes in the geometry of the substrate as result

${ }^{*}$ Corresponding author: 1.guz@ pollub.pl 
of the piezoelectric effect. In the case of using variable voltage at a constant frequency, cyclic vibrations cause the formation of an acoustic wave propagating on the surface of the substrate in direction to the output IDT. In the output IDT, the acoustic wave is converted into electric potential.

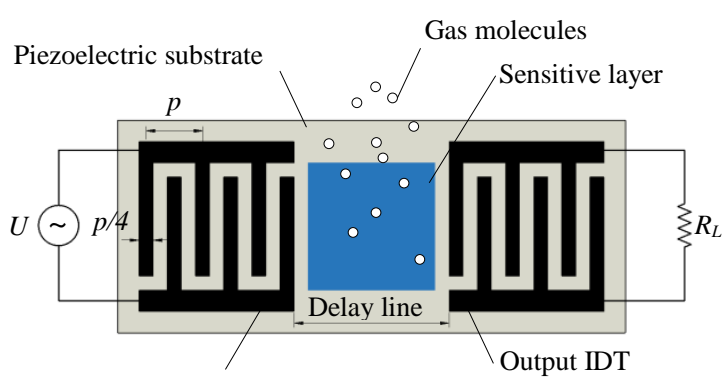

Input IDT

Fig. 1. Construction of SAW sensor.

IDT is fabricated as periodic metallic electrodes (fingers) deposited on the substrate in the form similar to interlocked combs. Electrodes should be made from metal with high electrical conductivity as well as good adhesion to substrate. Frequently used materials are: aluminium, platinum, platinum-based alloys, copper, gold, tungsten, titanium, conducting ceramics. Electrodes are fabricated using photolithography (etching or lift-off process) [17]. In the simplest form, the fingers width and clearance are identical. An increase in the length of fingers minimises wave dissipation. The magnitude of the output signal is maximal if the acoustic wavelength is equal to the distance between electrodes $p$. The corresponding frequency $f$ is called centre, synchronous or resonance frequency, and is calculated as:

$$
f=v / p
$$

where $v$ is velocity of acoustic wave.

The acoustic wave velocity depends on the substrate and is in the range from $1500 \mathrm{~m} / \mathrm{s}$ to $4800 \mathrm{~m} / \mathrm{s}$. This enables to create delay line in oscillation circuit because acoustic wave is $10^{5}$ lower than the electromagnetic wave velocity [18].

The moving acoustic wave is susceptible to distortions due to external factors, which are the basis for assessing the intensity of various phenomena. In this way, the physical strain values (pressure, stress, rotational speed) and temperature sensors are measured. The above-mentioned sensor feature is also used to create gas sensors. The surface between transducers is covered with a layer selectively adsorbing the particles of specific pollutants, both in gaseous or liquid state.

The change in the mass of the sensitive layer with adsorbed chemicals affects the change of the resonance frequency of the sensor. Using SAW sensors, it is possible to measure the mass change of even several nanograms [19].

Table 1. Physicochemical properties of selected gas sensors [13-16].

\begin{tabular}{|c|c|c|}
\hline Sensor type & Sensor advantages & Sensor disadvantages \\
\hline calorimetric & $\begin{array}{l}\text { fast sensor reaction, short return time to the } \\
\text { baseline }\end{array}$ & $\begin{array}{l}\text { high operating temperature, sensitive only to oxygen- } \\
\text { containing compounds }\end{array}$ \\
\hline catalytic & small sensor sizes, low measurement costs & $\begin{array}{l}\text { require environmental control, baseline drift, low } \\
\text { sensitivity to ammonia and carbon dioxide }\end{array}$ \\
\hline $\begin{array}{l}\text { conductive } \\
\text { polymers }\end{array}$ & $\begin{array}{l}\text { low measuring temperature, sensitive to many } \\
\text { volatile organic compounds, fast sensor reaction, } \\
\text { various sensor coverings, inexpensive }\end{array}$ & $\begin{array}{l}\text { susceptibility to poisoning the sensor, sensitive to } \\
\text { moisture and temperature, sensors can be } \\
\text { supersaturated by some compounds, limited, short } \\
\text { sensor life }\end{array}$ \\
\hline electrochemical & $\begin{array}{c}\text { low operating temperature, low energy } \\
\text { consumption, sensitive to many volatile organic } \\
\text { compounds }\end{array}$ & $\begin{array}{l}\text { significant sensor size, limited sensitivity for simple } \\
\text { compounds or low molar mass }\end{array}$ \\
\hline $\begin{array}{l}\text { oxide } \\
\text { semiconductor } \\
\text { (MOS) }\end{array}$ & $\begin{array}{l}\text { high sensitivity, rapid sensor response and return } \\
\text { of the signal to the baseline for compounds with } \\
\text { low molar mass }\end{array}$ & $\begin{array}{l}\text { high operating temperature, high energy } \\
\text { consumption, susceptible to sulphur poisoning and } \\
\text { weak acids, limited types of sensor coverings, } \\
\text { sensitive to dampness, poor precision }\end{array}$ \\
\hline optical & $\begin{array}{l}\text { high sensitivity, ability to distinguish individual } \\
\text { compounds in a mixture, ability to measure many } \\
\text { parameters }\end{array}$ & $\begin{array}{l}\text { complicated sensor array systems, expensive to run, } \\
\text { susceptible to mechanical damage, limited mobility }\end{array}$ \\
\hline $\begin{array}{l}\text { quartz } \\
\text { microbalances } \\
(\mathrm{QMB})\end{array}$ & $\begin{array}{l}\text { high precision, wide range of active element } \\
\text { covers, high sensitivity }\end{array}$ & $\begin{array}{l}\text { complicated electronics, low signal-to-noise ratio, } \\
\text { sensitive to humidity and temperature }\end{array}$ \\
\hline $\begin{array}{l}\text { surface acoustic } \\
\text { wave (SAW) }\end{array}$ & $\begin{array}{l}\text { sensitivity, good response time, inexpensive, small, } \\
\text { sensitive to many compounds }\end{array}$ & complicated electronic circuits \\
\hline
\end{tabular}


The measured frequency shift of sensors is proportional to the mass of particles deposited on the sensing layer and can be practically expressed by equation [20]:

$$
\Delta f=-\frac{\rho_{f} h_{f}}{\rho_{f} v} f_{0}^{2}
$$

where $\rho_{f}$ and $\rho_{s}$ are the densities of a film and a substrate, respectively, $h_{f}$ is the thickness of the film and $f_{o}$ the central frequency of the device. This method is accurate, provided that the film is thin (no more than a few percent of the acoustic wavelength).

The relation between the deposited mass of gas molecules and gas concentration could be determined numerically; nevertheless, the calibration of gas sensor is usually performed. Example resonant frequency $f_{o}$ shift of SAW sensor coated with poly (biscyanopropylsiloxane) as a function of concentration change of dimethyl methylphosphonate is presented in Fig. 2 .

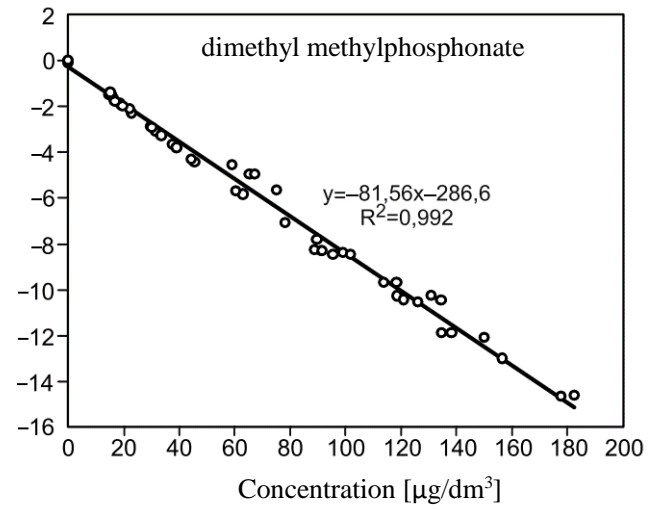

Fig. 2. Example resonant frequency $f_{o}$ shift of SAW sensor coated with poly(biscyanopropylsiloxane) as a function of concentration change of dimethyl methylphosphonate [21].

\subsection{Sensing layer}

An important issue while choosing a sensitive layer are both physical and chemical properties. An optimal sensitive layer should:

- be stable, selective, sensitive,

- be uncomplicated during creation and repetitive,

- be electrically non-conductive,

- form a strong bond with the substrate,

- create reversible and repeatable interactions with analytes,

- non-susceptible to environmental factors and disturbances,

- be characterised by dominant physisorption instead of chemisorption.

The adsorbent layer should have good properties of both sorption and desorption. After the measurements, the sensitive layer should return to the original state. This process is accelerated by flushing the sensor with clean air.

Conducting or non-conducting polymers and their derivatives are most often used in scientific research [22]. These materials lack good selective properties.
Their popularity results from the simplicity of the coating (spin coating or drop casting), they also have a short response time and return to the initial state [23]. They are used to detect various VOCs such as alcohols, aromatics and some inorganic compounds.

Sensitive layers with metal-oxides are useful for detecting inorganic compounds. However, these layers require operation at higher temperatures [24]. In these sensors, chemisorption and redox reactions prevail; therefore, they show a longer response time and return to the initial state. Carbon nanostructures are used as a sensing materials, including carbon nanotubes (CNT) [25] or graphene oxide [26]. Other materials, such as metals [27], ceramics [28] and composite materials [29] are used as well.

In recent years, the interest in the application of biomaterials in sensitive layers has been growing [30]. For this purpose, odorant-binding proteins (OBP) derived from different organisms are applied [31]. Different cells or specially isolated nanovesicles were also examined [32, 33]. The biosensors formed in this way show high sensitivity and selectivity. However, there are important issues that hinder the practical application of biosensors. One of them is the lack of reproducibility of biomaterial deposition on the carrier and difficulties in obtaining stable and reproducible measurement results.

\subsection{Substrate materials}

The SAW sensor substrate is made of piezoelectric material, usually in the form of a plate cut from quartz, lithium tantalate, lithium niobate or langasite. Some common piezoelectric materials used as substrate of SAW sensors are summarised in Tab.2. The substrate material and cut orientation strongly affect the crystal parameters such as acoustic wave propagation mode, electromechanical coupling coefficient, temperature coefficient (TC), acoustic wave velocity $v$. The materials with low TC are preferred; therefore, the ST-X quartz crystallographic orientation is very popular.

Different modes of wave propagation are utilised in the substrate of SAW sensor: Rayleigh waves, shear horizontal $(\mathrm{SH})$ waves, surface transverse waves, Love waves or Lamb waves. Each of these waves is characterised by different properties, showing specific sensitivity to the measured parameters.

Table 2. Common piezoelectric materials used as substrate of SAW sensors [23]

\begin{tabular}{|c|c|c|}
\hline Substrate & $\begin{array}{c}v \\
{[\mathrm{~m} / \mathrm{s}]}\end{array}$ & $\begin{array}{c}\text { Temp. coef. } \\
{\left[\mathrm{ppm} /{ }^{\circ} \mathrm{C}\right]}\end{array}$ \\
\hline $\mathrm{ST} \mathrm{X}$ Quartz & 3159 & 0 \\
\hline $\mathrm{Y}-\mathrm{Z} \mathrm{LiNbO}_{3}$ & 3487 & 94 \\
\hline $128 \mathrm{Y}-\mathrm{X} \mathrm{LiNbO} 3$ & 3992 & 75 \\
\hline $64 \mathrm{Y}-\mathrm{X} \mathrm{LiNbO}{ }_{3}$ & 4742 & 80 \\
\hline $\mathrm{Y}-\mathrm{Z} \mathrm{LiTaO}_{3}$ & 3230 & 35 \\
\hline $\mathrm{X}-112 \mathrm{Y} \mathrm{LiTaO}$ & 3301 & 18 \\
\hline$(0001) \mathrm{AlN}_{3}$ & 5607 & 19 \\
\hline$(001)-<110>\mathrm{GaAs}$ & 2864 & 35 \\
\hline $\mathrm{ZnO}$ & 2645 & 15 \\
\hline
\end{tabular}


In the case of typical SAW sensors, the Rayleigh waves are very useful. Rayleigh waves include both longitudinal and transverse motions that decrease exponentially in amplitude as the distance from the surface increases. For example, Rayleigh waves in liquid environment exhibit a significant loss of amplitude energy; therefore, the SH waves are preferred.

\subsection{Measurements circuits}

The measurements using SAW sensors can be based on analysis of changes:

amplitude and phase of the signal,

frequencies,

acoustic wave velocity.

The change of properties of the acoustic wave, due to the surface perturbation, can be mo

nitored by measuring the phase change and acoustic losses, e.g. by using a network analyser. Nonetheless, the most common method of analysis is to determine the changes in the resonant frequency of sensor and the speed of the wave by determining the change in the resonance frequency of the system. The oscillator scheme is shown in Fig. 3 In this system, the delay line is placed in the feedback loop of an electronic amplifier. If the oscillation conditions are fulfilled, oscillation occurs, giving an output frequency which is related to the phase of the wave. The oscillations are sustained if the following conditions are met:

amplification in the open loop is greater than 1 , net phase in the closed loop (acoustical and electrical) equals $2 n \pi$, where $n$ is the number of the mode according to the following equation:

$$
\frac{2 \pi f L}{v}+\Phi_{A}(f)=2 \pi n
$$

where $f$ is the oscillation frequency, and $\Phi_{A}$ is the phase of the amplifier [20].

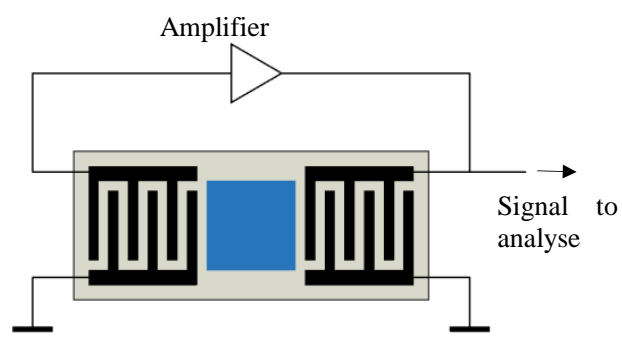

Fig. 3. Basic measurement scheme with feedback amplifier.

In order to compensate the effect of temperature on test results, an additional reference delay line is used in the form of clean sensor, not covered with the sensitive layer (Fig.4). As a result of summarising signals in the mixer, an output signal without a temperature component is obtained.

In electronic nose, it is convenient to use external oscillation system with stepped or linear frequency change. It gives a possibility of a more complete insight into the SAW sensor properties. A general scheme of multichannel device (e-nose) is presented in fig. 5. In the device, many SAW sensors could be implemented in the measuring circuit. Sinusoidal signal is generated in digital frequency synthesizer and processed in an amplifier. The frequency of signal is tuned by control unit. Selection of proper SAW sensor is performed via channel multiplexers. The phase and amplitude evaluation are performed for the output signal from the sensors.



Fig. 4. Basic measurement scheme with feedback amplifier.

In contrast to the analogue circuit presented previously in fig. 3 , this system enables to evaluate the sensor amplitude-phase response in a broad range of frequencies.

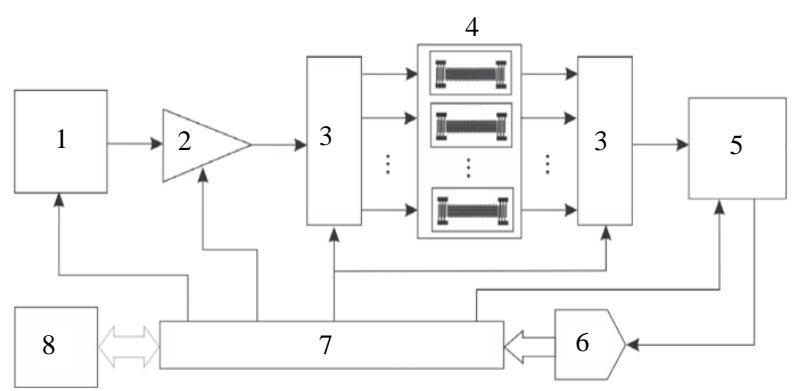

Fig. 5. Measurement schema with external excitation: 1) digital synthesis of signal, 2) amplifier, 3) channel multiplexer, 4) SAW sensors, 5) amplitude and phase detector, 6) analogue/ digital converter, 7) control and data acquisition unit, 8) computer [34].

\section{Conclusion}

The SAW sensors are currently often used in electronic nose systems. The possibility of coating them with various adsorptive layers, improving their sensitivity and selectivity, contribute to their popularity. More and more studies are conducted on the biosensors based on SAW sensors. The advantage of acoustic sensors is operation at ambient temperature, in contrast to the MOS sensors, whose sensing element must work at high temperature. SAW sensors have extremely low power consumption and additionally the possibility of wireless operation in an interrogation mode is an interesting feature. However, in order to achieve a wider industrial application, the research on improving the durability of these sensors, the reproducibility of their structure - especially the sensory layer - and repeatability of measurement results, should be carried out simultaneously. 


\section{References}

1. I. Sówka, M. Skrętowicz, M. Szklarczyk, J. Zwoździak, Environ. Prot. Eng. 37, 1, 5-12 (2011)

2. I. Sówka, U. Miller, A. Grzelka, Environ. Prot. Eng. 43, 4 (2017).

3. I. Sowka, U. Kita, M. Skretowicz, A. Nych, J. Zwozdziak, Annual Set The Environ. Protection 15, 2, 1207-1215 (2013)

4. PN-EN 13725 Air Quality-Determination of Odour Concentration by Dynamic Olfactometry (2013)

5. J.W. Gardner, H.W. Shin, E.L. Hines, Sensors Actuators B Chem. 70, 1-3, 19-24 (2000)

6. M. Śliwińska, P. Wiśniewska, T. Dymerski, J. Namieśnik, W. Wardencki, J. Agric. Food Chem. 62, 7, 1423-1448 (2014)

7. M. Gancarz, J. Wawrzyniak, M. GawrysiakWitulska, D. Wiącek, A. Nawrocka, M. Tadla, R. Rusinek, Measurement 103, 227-234 (2017)

8. M. Gancarz, J. Wawrzyniak, M. GawrysiakWitulska, D. Wiącek, A. Nawrocka, R. Rusinek, Int. Agrophysics 31, 3, 317-325 (2017)

9. Z. Suchorab, H. Sobczuk, Ł. Guz i G. Łagód Gas sensors array as a device to classify mold threat of the buildings. In: Environmental Engineering V Proceedings of the 5th National Congress of Environmental Engineering, 203-209 (2017)

10. Ł. Guz, G. Łagód, Z. Suchorab, H. Sobczuk i E. Kurek, Application of an electronic nose for odour nuisance evaluation of wastewater treatment plant devices (Water supply and wastewater removal, 3053, Lublin 2016)

11. Ł. Guz, G. Łagód, K. Jaromin-Gleń, E. Guz, H. Sobczuk, Desalin. Water Treat. 57, 3, 1327-1335 (2016)

12. A. Bieganowski, K. Jaromin-Glen, Ł. Guz, G. Łagód, G. Jozefaciuk, W. Franus, Z. Suchorab, H. Sobczuk, Sensors 16, 6, 886 (2016)

13. A.D. Wilson, M. Baietto, Sensors 9, 5099-5148 (2009)

14. P. Mielle, F. Marquis, Sensors Actuators B 68, 9-16 (2000)

15. K. Arshak, G.M. Lyons, C. Cunniffe, J. Harris, S. Clifford, Sens. Rev. 23, 4, 332-344 (2003)
16. D. James, S.M. Scott, Z. Ali, W.T. O'Hare, Microchim. Acta 149, 1-17 (2004)

17. J. Kirschner, Microelectromechanical Systems 12, 1-11 (2010)

18. M.J. Vellekoop, Ultrasonics 36, 1-5, 7-14 (1998)

19. J.D.N. Cheeke, Z. Wang, Sensors Actuators B Chem. 59, 2-3, 146-153 (1999)

20. M.F. Hribšek, D. V. Tošić, M.R. Radosavljević, FME Trans. 38, 11-18 (2010)

21. M. Grabka, K. Jasek, J. Choma, Ochr. Srodowiska 40, 2, 9-16 (2018)

22. A. Mujahid, F.L. Dickert, SAW and Functional Polymers. In: C.D. Kohl, T.Wagner (ed.), Gas Sensing Fundamentals, 213-245, Berlin (2013)

23. J. Devkota, P. Ohodnicki, D. Greve, J. Devkota, P.R. Ohodnicki, D.W. Greve, Sensors 17, 4, 801 (2017)

24. V.B. Raj, H. Singh, A.T. Nimal, M. Tomar, M.U. Sharma, V. Gupta, Sensors Actuators B Chem. 187, 563-573 (2013)

25. I. Sayago, M.J. Fernandez, J.L. Fontecha, M.C. Horrillo, E. Terrado, A. Seral-Ascaso, E. Munoz, Carbon nanotube-based SAW sensors. Spanish Conference on Electron Devices, 127-130 (2013)

26. S. Xu, C. Li, H. Li, M. Li, C. Qu, B. Yang, J. Mater. Chem. C 3, 16, 3882-3890 (2015)

27. D. Sil, J. Hines, U. Udeoyo, E. Borguet, ACS Appl. Mater. Interfaces 7, 10, 5709-5714 (2015)

28. C. Tasaltin, M.A. Ebeoglu, Z.Z. Ozturk, Sensors 12, 9, 12006-12015 (2012)

29. A.Z. Sadek, W. Wlodarski, K. Shin, R.B. Kaner, K. Kalantar-zadeh, Nanotechnology 17, 17, 4488-4492 (2006)

30. K. Länge, F.J. Gruhl, M. Rapp, Methods Mol. Biol. 949, 491-505 (2013)

31. F. Di Pietrantonio, D. Cannatà, M. Benetti, E. Verona, A. Varriale, M. Staiano, S. D'Auria, Biosens. Bioelectron. 41, 328-334 (2013)

32. T. Wasilewski, J. Gębicki, W. Kamysz, Biosens. Bioelectron. 87, 480-494 (2017)

33. T. Wasilewski, J. Gębicki, W. Kamysz", Sensors Actuators B Chem. 257, 511-537 (2018)

34. M. Grabka, K. Jasek, M. Pasternak, W. Miluski, Apar. Badaw. i Dydakt. 20, 4, 251-258 (2015). 